\title{
Sesamin stimulates osteoblast differentiation through p38 and ERK1/2 MAPK signaling pathways
}

Orawan Wanachewin ${ }^{1 \dagger}$, Kanchanit Boonmaleerat ${ }^{1 \dagger}$, Peraphan Pothacharoen $^{1}$, Vichai Reutrakul ${ }^{2}$ and Prachya Kongtawelert ${ }^{1 *}$

\begin{abstract}
Background: Osteoporosis is a worldwide health problem predominantly affecting post-menopausal women. Therapies aimed at increasing bone mass in osteoporetic patients lag behind comparable investigation of therapeutic strategies focusing on the bone resorption process. Sesamin, a major lignan compound found in Sesamun indicum Linn., has a variety of pharmacological effects, though its activity on bone cell function is unclear. Herein we examine the effect of this lignan on osteoblast differentiation and function.

Method: Cell cytotoxicity and proliferative in hFOB1.19 were examined by MTT and alamar blue assay up to $96 \mathrm{~h}$ of treatment. Gene expression of COL1, ALP, BMP-2, Runx2, OC, RANKL and OPG were detected after $24 \mathrm{~h}$ of sesamin treatment. ALP activity was measured at day 7,14 and 21 of cultured. For mineralized assay, ADSCs were cultured in the presence of osteogenic media supplement with or without sesamin for 21 days and then stained with Alizarin Red S. MAPK signaling pathway activation was observed by using western blotting.

Results: Sesamin promoted the gene expression of COL1, ALP, OCN, BMP-2 and Runx2 in hFOB1.19. On the other hand, sesamin was able to up-regulate OPG and down-regulate RANKL gene expression. ALP activity also significantly increased after sesamin treatment. Interestingly, sesamin induced formation of mineralized nodules in adipose derived stem cells (ADSCs) as observed by Alizarin Red S staining; this implies that sesamin has anabolic effects both on progenitor and committed cell stages of osteoblasts. Western blotting data showed that sesamin activated phosphorylation of p38 and ERK1/2 in hFOB1.19.

Conclusions: The data suggest that sesamin has the ability to trigger osteoblast differentiation by activation of the p38 and ERK MAPK signaling pathway and possibly indirectly regulate osteoclast development via the expression of $O P G$ and RANKL in osteoblasts. Therefore, sesamin may be a promising phytochemical that could be developed for supplementation of osteoporotic therapy.
\end{abstract}

\section{Background}

Osteoporosis, the most common metabolic bone disease, is characterized by low bone density and deterioration of bone micro-architecture [1]. This bone disease results from an imbalance in the bone remodeling process. Both a high rate of bone resorption and insufficiency of bone formation cause patients to develop bone fragility and

\footnotetext{
* Correspondence: prachya.kongtawelert@gmail.com

${ }^{\dagger}$ Equal contributors

'Thailand Excellence Center for Tissue Engineering and Stem Cells, Department of Biochemistry, Faculty of Medicine, Chiang Mai University, Chiang Mai 50200, Thailand

Full list of author information is available at the end of the article
}

possibly leading to bone fractures. The standard therapeutic drugs for osteoporosis include anti-resorptive drugs such as bisphosphonate, osteocalcin and estrogen, although these have little ability to stimulate new bone synthesis, which is important for patients with advanced bone loss [2-4]. Therefore, investigation of agents that improve bone formation is important as well.

Osteoblasts, or bone forming cells, are derived from mesenchymal stem cells (MSCs) that are also the progenitors of myocytes, chondrocytes and adipocytes [5]. Enhancement of osteoblast proliferation and differentiation can ameliorate both the quantity and quality of bone tissue. Osteoblast maturation and differentiation

\section{Biomed Central}

(c) 2012 Wanachewin et al.; licensee BioMed Central Ltd. This is an Open Access article distributed under the terms of the Creative Commons Attribution License (http://creativecommons.org/licenses/by/2.0), which permits unrestricted use, distribution, and reproduction in any medium, provided the original work is properly cited. 
can be modulated through many kinds of environmental factors and signaling cascades [6-8]. Bone morphogenetic proteins (BMPs), a members of transforming growth factors (TGFs) are known to be essential for regulating osteoblast differentiation, especially via the Smad-dependent signaling pathway [9]. Meanwhile, cross-talk among other signaling pathways may also be involved in osteoblastogenesis.

Mitogen-activated protein kinase (MAPK) signaling occurs in many cells and involves in cell survival, proliferation and differentiation [10-13]. Many previous studies have shown that the expression of osteoblastogenic genes and functions are stimulated by MAPK signaling [14]. For example, the constitutively active form of ERK2 activates osteoblast differentiation both in vitro and in vivo $[15,16]$ and p38 involves phosphorylation of smad-1 thus resulting in ALP expression and activation of osteoblasts [17].

Sesame seeds (Sesamun indicum L.) are widely used as dietary supplements. The plant is widely cultivated in Asian and African countries. The oil from the seed contains various phytochemical compounds that display medicinal properties. Jeng and Hou reported that health benefits of sesame seeds may be attributed to its lignans, especially sesamin [18]. Sesamin affects lipid metabolism, contributes to reduced incidence of tumorigenesis, and has the ability to protect neuronal cells against oxidative stress. The preventive ability of lignans on bone loss was reported [19], but effect on the bone formation process has as yet not been examined.

This study aimed to investigate sesamin's effects on osteoblast differentiation by examination of osteoblastogenic related gene expression, ALP activity, the mineralization process, and an activation of p38 and ERK $1 / 2$ in the MAPK pathway. We also examined sesamin's effect on OPG/RANKL gene expression, the important regulators of osteoclast differentiation.

\section{Methods}

\section{Cell culture and treatment}

Human fetal osteoblast cell line (hFOB1.19, CRL NO.11372) was purchased from ATCC and expanded in a 1:1 mixture of phenol red-free DMEM/Ham's F-12 medium (Sigma-Aldrich) supplemented with 10\% fetal bovine serum (FBS), $100 \mathrm{U} / \mathrm{mL}$ penicillin and $100 \mu \mathrm{g} /$ $\mathrm{mL}$ streptomycin (basal media). Cells were incubated at a temperature of $33.5{ }^{\circ} \mathrm{C}$ with $95 \%$ air $5 \% \mathrm{CO}_{2}$.

Human adipose derived stem cells (ADSCs) were purchased from Invitrogen. The cells were maintained in DMEM (Gibco) containing 10\% FCS, $100 \mathrm{U} / \mathrm{mL}$ penicillin, $100 \mu \mathrm{g} / \mathrm{mL}$ streptomycin and were incubated at $37{ }^{\circ} \mathrm{C}$ with $95 \%$ air $5 \% \mathrm{CO}_{2}$. The media was changed every three days. For osteogenic induction, additional components were $50 \mu \mathrm{g} / \mathrm{ml} \mathrm{L-ascorbic} \mathrm{acid} \mathrm{(Sigma-Aldrich),}$
$10^{-7} \mathrm{M}$ dexamethasone (Sigma-Aldrich) and $10 \mathrm{mM} \beta$ glycerophosphate (Fluka).

\section{Cell cytotoxicity assay}

hFOB1.19 and ADSCs were plated in 96-well plates at a density of $5 \times 10^{3}$ cells per well. Twenty-four hours after plating, the cells were exposed to $0.3-20 \mu \mathrm{g} / \mathrm{ml}$ sesamin for an additional 24, 48, 72 and 96 hours. Each treatment was carried out in triplicate. At the end of the treatment, $10 \mu \mathrm{l}$ of MTT solution $(0.5 \mathrm{mg} / \mathrm{ml}$ in PBS) was added to each well and the plate was incubated in a $\mathrm{CO}_{2}$ incubator at $37^{\circ} \mathrm{C}$ for four hours prior to the buffer being decanted, and $100 \mu$ DMSO was added to dissolve the formazan crystals. Optical density was measured at a wavelength of $540 \mathrm{~nm}$ using an ELISA plate reader. The percentage of cell viability was calculated by the equation:

$\%$ of cell survival $=($ OD of sample $/ O D$ of control $) \times 100$

\section{Cell proliferation assay}

hFOB1.19 treatment were performed as described for the cytotoxic assay. At indicated time of treatment, alamar blue dye $(10 \% \mathrm{v} / \mathrm{v}$ in culture medium) was added to each well and incubated again at $37{ }^{\circ} \mathrm{C}$ for four hours before the absorbance was measured at $540 \mathrm{~nm}$ (test wavelength) and $630 \mathrm{~nm}$ (reference wavelength) using a Titertek Multiskan M340 multiplate reader.

\section{RNA extraction and gene expression analysis}

For examination of gene expression, hFOB1.19 was exposed to sesamin at $1.0,2.5,5.0$ and $10.0 \mu \mathrm{g} / \mathrm{ml}$ for 24 hours. After that, the total RNA was extracted using Nucleospin ${ }^{\circledR}$ RNA II (Machere-Nagel) following the manufacturer's instructions. The total RNA (2 $\mu \mathrm{g})$ was reversibly transcribed to cDNA using the RevertAid ${ }^{\mathrm{TM}}$ $\mathrm{H}$ First Strand cDNA Synthesis kit (Fermentas). Realtime quantitative polymerase chain reaction was performed in a DNA Engine (ABi 7500) using SYBR GREENER qPCR UNIVERSAL (Invitrogen), primer sequences as indicated in Table 1. Relative expression levels for each primer set were normalized to the expression of GAPDH by $2^{-\mathrm{CT}}$ method [20].

\section{Assessment of alkaline phosphatase activity}

Cells were seeded in 24-well plates and treated with sesamin at 5 and $10 \mu \mathrm{g} / \mathrm{ml}$ up to 14 days. For all experiment periods, cells were maintained in osteogenic media, and media was changed every three days. ALP activity was detected using an alkaline phosphatase detection kit (Sigma-Aldrich). Briefly, the conditioned media were collected and $20 \mu \mathrm{l}$ of media were incubated at $65{ }^{\circ} \mathrm{C}$ to diminish the background activity. Then 
Table 1 Primers used for real time-qPCR

\begin{tabular}{|c|c|c|}
\hline Gene & $\begin{array}{l}\text { Sequence }\left(5^{\prime}-3^{\prime}\right) \text { : } \\
\text { Forward }(F) \text {; Reverse }(\mathrm{R})\end{array}$ & $\begin{array}{l}\text { Accession } \\
\text { number }\end{array}$ \\
\hline \multirow[t]{2}{*}{$A L P$} & F:CATGGCTTTGGGCAGAAGGA & NM_001114107.2 \\
\hline & R:CTAGCCCCAAAAAGAGTTGCAA & \\
\hline \multirow[t]{2}{*}{ BMP-2 } & F:ATGGATTCGTGGTGGAAGTC & NM_001200.2 \\
\hline & R:GTGGAGTTCAGATGTCAGC & \\
\hline \multirow[t]{2}{*}{ Type I Collagen } & F:CAGCCGCTTCACCTACAGC & NM_000088.3 \\
\hline & R:TTTTGATTCAATCACTGTCTTGCC & \\
\hline \multirow[t]{2}{*}{ RANKL } & F: CACTATTAATGCCACCGAC & NM_033012.3 \\
\hline & R: GGGTATGAGAACTTGGGATT & \\
\hline \multirow[t]{2}{*}{ Runx2 } & F: GCCTTCAAGGTGGTAGCCC & NM_001024630.2 \\
\hline & R: CGTTACCCGCCATGACAGTA & \\
\hline \multirow[t]{2}{*}{$O C$} & F: GAAGCCCAGCGGTGCA & NM_199173.2 \\
\hline & R: CACTACCTCGCTGCCCTCC & \\
\hline \multirow[t]{2}{*}{$O P G$} & F: CCTCTCATCAGCTGTTGTGTG & NM_002546.3 \\
\hline & R: TATCTCAAGGTAGCGCCCTTC & \\
\hline \multirow[t]{2}{*}{ GAPDH } & F:GAAGGTGAAGGTCGGAGTC & NM_002046.3 \\
\hline & R:GAAGATGGTGATGGGATTTC & \\
\hline
\end{tabular}

samples were mixed with a reaction buffer, which contained 4-methylumbelliferyl phosphate disodium salt as substrate. Fluorescence at UV light wavelengths from $360 / 440 \mathrm{~nm}$ was measured with a multi-detection microplate fluorometer (Synergy ${ }^{\mathrm{TM}} \mathrm{HT}$ ). The conditional medium of the day 3, 7 and 14 were measured for ALP activity and normalized with total protein level.

\section{Mineralization assay}

ADSCs were stained with Alizarin Red S on day 21 of treatment for assessing the mineralized nodules. The medium was removed, and the cell layers were rinsed three times with PBS and fixed with 95\% ethanol at room temperature for $15 \mathrm{~min}$. Then, the cell layers were washed twice with deionized water. The fixed cells were stained with $2 \mathrm{ml}$ of $40 \mathrm{mM}$ Alizarin red-S (pH 4.0 - 4.5) per culture dish. After incubation at room temperature for $20 \mathrm{~min}$, the cell layers were washed four times with an excess of deioinized water and observed under an inverted light microscope (Olympus BX41). For the quantitative method, stained cells were extracted and normalized with $10 \%$ acetic acid and 10\% ammonium hydroxide respectively [21]. The absorbance of the solution was read at $405 \mathrm{~nm}$ in triplicate and calculated from the staining level using a standard curve.

\section{Western blotting}

hFOB1.19 treated with sesamin for the indicated time and concentrations were lysed with a sample buffer containing 5\% mercaptoethanol. For western blotting, the samples were subject to $12 \%$ gel SDS-PAGE. Then, the separated proteins were transferred to a nitrocellulose membrane (Amersham Pharmacia Biotech). The membrane was blocked for one hour with $5 \%$ skim milk in TBS and then incubated with specific primary antibody which are p38, ERK, JNK, phosphorylated p38, phosphorylated ERK, and phosphorylated JNK (Cell Signaling Technology) overnight at $4^{\circ} \mathrm{C}$. After triplicate washing with TBS-Tween, the specific protein bands were probed with horseradish peroxide-labeled secondary antibody (Cell Signaling Technology) for one hour. Finally, the membranes were developed using an ECL kit (KPL).

\section{Statistical analysis}

Data were expressed as means \pm S.D. Statistically significant differences between the means of control and test group were assessed by independent $T$-test using SPSS software. p-value less than $0.05\left(^{*}\right)$ and $0.01\left(^{* * *}\right)$ were considered a significant difference.

\section{Results}

Sesamin did not affect cell viability and proliferation

Prior to the analysis of the anabolic effects of sesamin, the cytotoxicity on hFOB1.19 and ADSCs were investigated using the MTT assay, which is a reliable and widely used method of assessing cell viability based on mitochondrial enzyme activity [22]. After treatment with sesamin for $24,48,72 \mathrm{~h}$, sesamin at various concentrations $(0.3-20 \mu \mathrm{g} / \mathrm{ml})$ had no cytotoxicity effect on hFOB1.19 and ADSCs, cells survival, as illustrated by the percentages of cellviability, which were more than $80 \%$ of those of the control group (Figure $1 \mathrm{~A}$ and $\mathrm{B}$ ). Besides, to examine whether sesamin had an effect on osteoblast proliferation, an alamar blue assay was performed. After 24, 48, 72 and 96 hours treatment, sesamin had no significant effect on the proliferation rate on human osteoblast cells (Figure $1 \mathrm{C}$ ).

\section{Sesamin up-regulated osteoblastogenic genes}

During the bone formation process, there is increased expression of specific genes in osteoblasts; these genes play roles in extracellular matrix formation and mineral deposition. In order to study the anabolic effect of sesamin, we examined mRNA expression of alkaline phosphatase $(A L P)$, bone morphogenetic protein-2 (BMP$2)$, runt related protein 2 (Runx2), type I collagen, and osteocalcin (OC). COL1, ALP and BMP-2 were highly up-regulated in the presence of sesamin. At the highest dose $(10 \mu \mathrm{g} / \mathrm{ml})$, expression levels of those genes were up to 7 -fold, 15 -fold and 20 -fold increased relative to control, respectively (Figure 2A). Additionally, significantly increased expression of Runx2 transcription factor and osteocalcin were observed in the culture with sesamin treatment (Figure 2B). 

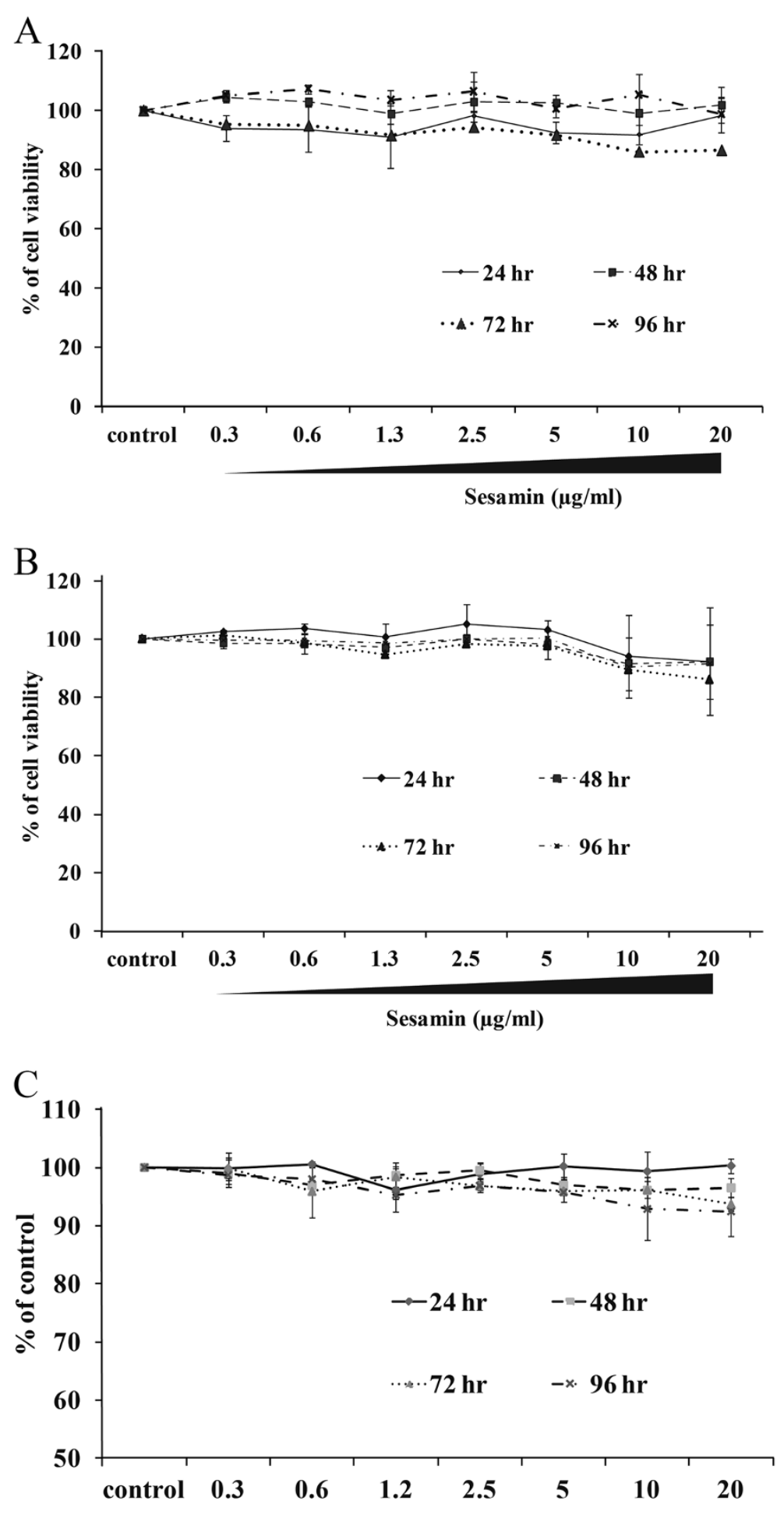

Sesamin $(\mu \mathrm{g} / \mathrm{ml})$

Figure 1 The effects of sesamin on cytotoxicity of hFOB1.19 (A) ADSCs (B) and proliferation of hFOB1.19 (C) were examined at 24, 48, 72 and $96 \mathrm{~h}$ after sesamin treatment $(\mathbf{0 . 3}-20 \mu \mathrm{g} / \mathrm{ml})$. Data are shown as mean \pm S.D. of three independent experimets. Statistical analysis was analyzed by independent $T$-test, $p<0.05$. 

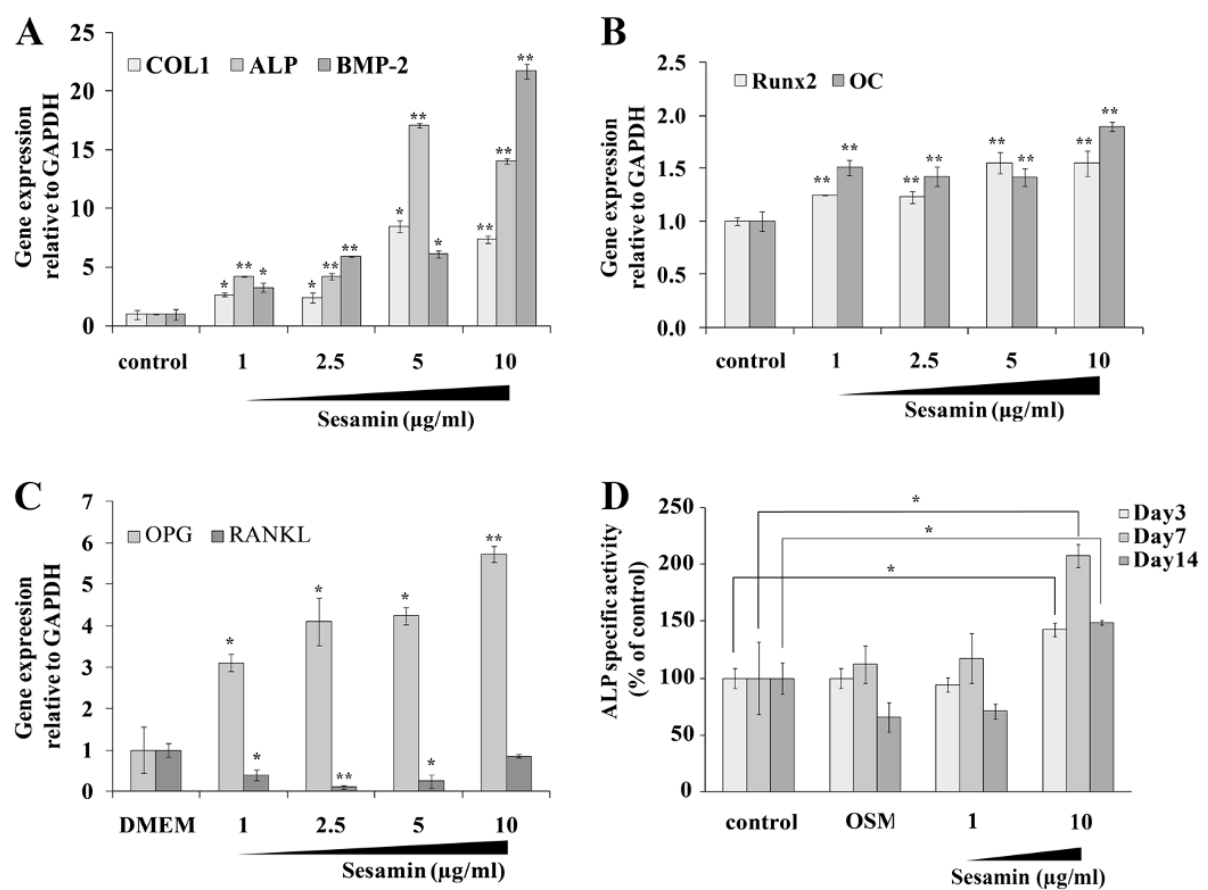

Figure 2 Gene expression analysis and enzymatic activity of osteoblastogenic markers, for gene expression, $24 \mathrm{~h}$ FCS deprived hFOB1.19 cells were cultured in the presence of sesamin at indicated concentrations for another $24 \mathrm{~h}$. CDNA of each samples was analyzed by Real-time PCR. The expression of COL1, ALP, and BMP-2 (A) The expression of Runx2 and OC. (B) The expression of OPG and its counterpart RANKL (C) ALP activity was detected in culture media at days 3, 7 and 14 of culture using an alkaline phosphatase detection kit (D). All data are shown as mean \pm S.D. of three independent experiments. Statistical analysis was analyzed by independent $T$-test, ${ }^{*}$ and ${ }^{* *}$ denoted for $p$-value $\leq 0.05$ and 0.01 , respectively.

\section{Osteoclast differentiation may be regulated by sesamin} via osteoblasts

Many studies have suggested that osteoclast differentiation is controlled by the action of the osteoblastic lineage through the RANKL/RANK/OPG system [23]. RANKL activates the development of pre-osteoclasts to become mature osteoclasts, while osteoprotegerin or OPG serves as a secreted receptor of RANKL (decoy receptor), resulting in inhibition of RANKL binding to its cell surface receptor and activation of osteoclast maturation. Because
A

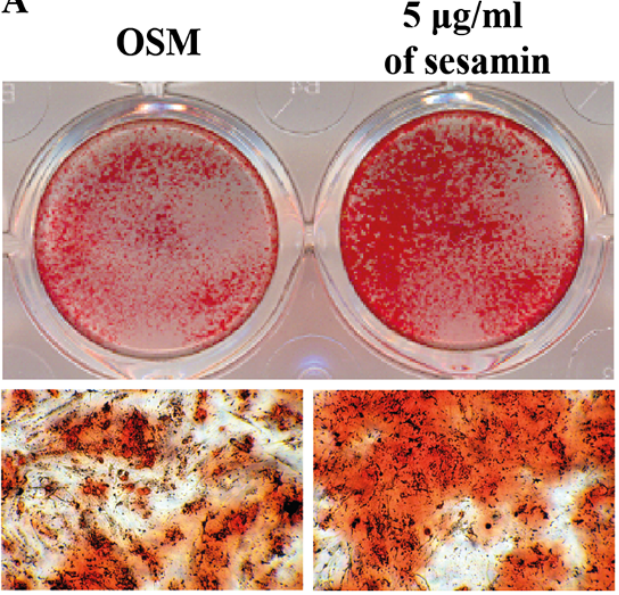

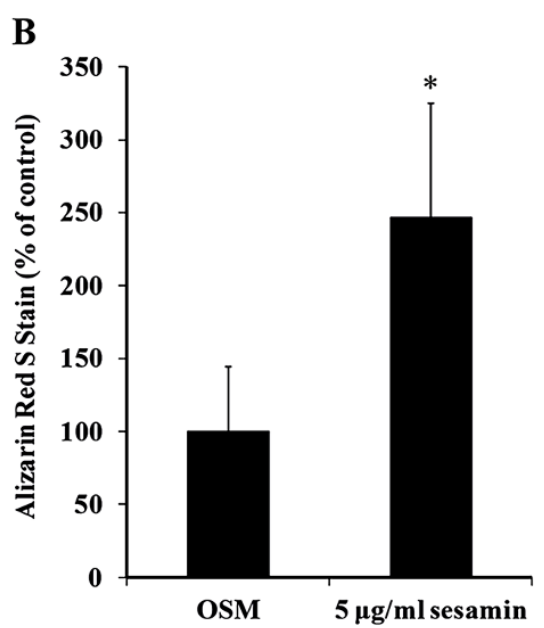

Figure 3 Osteoblast differentiation of ADSCs was determined by Alizarin Red S staining. Plate view (upper) and microscopic view (lower) of the staining on day 21 of sesamin treatment (A). Intensity of Alizarin Red S stains, which relative to quantity of mineralization process, were examined (B). Graph data are shown as mean \pm S.D. of three independent experiments. 

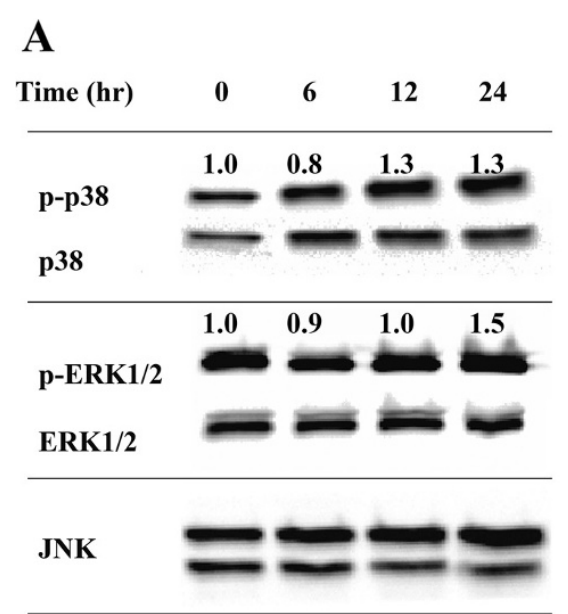

B

\begin{tabular}{lcccccc}
$\begin{array}{l}\text { Sesamin } \\
(\mu \mathrm{g} / \mathrm{ml})\end{array}$ & 0 & 1.0 & 2.5 & 5.0 & 10.0 \\
\hline $\mathrm{p}-\mathrm{p} 38$ & 1.0 & 1.0 & 0.8 & 1.2 & 1.4 \\
$\mathrm{p38}$ & & & & & & \\
\hline p-ERK1/2 & 1.0 & 0.9 & 1.2 & 1.2 & 8.8 \\
ERK1/2 & & & & & &
\end{tabular}

JNK

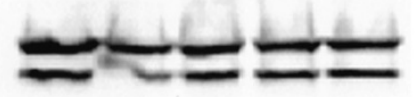

Figure 4 MAPK signaling protein activation under vary times and concentration of sesamin treatment on hFOB1.19 by western blotting. The numbers denoted the quality density value based on Quantity One 4.6.5 software. The MAPK signaling activation under vary time treatment (0-24 h) (A). The MAPK signaling activation under different concentration of sesamin treatment (B). The data is representative of three independent studies.

RANKL and $O P G$ are both synthesized by the osteoblastic lineage, it is worthwhile to examine the expression levels of these genes under sesamin treatment. After $24 \mathrm{~h}$ of treatment, sesamin $(2.5$ and $5.0 \mu \mathrm{g} / \mathrm{ml})$ up-regulated $O P G$ gene expression, while the expression of RANKL was significantly decreased (Figure $2 \mathrm{C}$ ). According to these results, sesamin might have an indirect inhibitory effect on osteoclasts via osteoblast function.

\section{ALP activity was stimulated by sesamin treatment}

To verify the potential of sesamin on osteoblast differentiation, ALP activity was measured. Culture media were collected at days 3,7 , and 14 to measure ALP activity. Sesamin $(10 \mu \mathrm{g} / \mathrm{ml})$ significantly increased the enzyme activity at each date, while the highest stimulatory effect was observed on day seven, on which ALP activity levels were increased up to $208 \%$ compared with control. ALP activity of all treatments reached its highest levels on day 7 of the culture (Figure 2D). This result agreed with previous findings, that ALP is most highly expressed during the onset of the mineralization process, which lasts for about 7 days and decreases during later stages of bone formation [24].

\section{ADSCs were stimulated to form mineralized nodules by sesamin treatment}

According to unobvious report of Alizarin Red S staining in hFOB1.19 shown by others $[24,25]$ and undetectable of this stain performed in our sesamin treated hFOB1.19 that may be attributed to inadequate calcium supplement in recommend culture medium (DMEM/ HAM F'12). Thus, the mineralization assay was performed in ADSCs, which are well studies about differentiation capacity as same as stem cells from other sources [26,27]. After 21 days of treatment, ADSCs had the potential to form mineralized nodules, which were observed as a bright red field with Alizarin Red S staining (Figure 3A). Quantification of Alizarin Red showed that sesamin significantly promoted mineral deposition by ADSCs, nearly up to $250 \%$ of the OSM control (Figure 3B). This suggests that sesamin can stimulate bone cell differentiation and bone matrix formation by ADSCs.

\section{Acceleration of osteoblast differentiation by sesamin might be attributed to p38 and ERK 1/2 MAPK signaling pathways}

Although it is well documented that BMPs and Smad signaling pathways are enough to modulate bone cell growth and differentiation, cross-talking with other signaling pathways such mitogen activated kinase (MAPKs) are involved in bone formation. It has been reported that MAPK signaling mediate sesamin effects, therefore, we interested to test whether sesamin modulate osteoblast differentiation through MAPK signaling pathways. Sesamin treatment continuously increased phosphorylation of p38 and ERK in a time dependent manner $(6,12,24 \mathrm{~h})$. Band density analysis of signaling protein normalized to total form at $24 \mathrm{~h}$ treatment showed that sesamin $(5.0 \mu \mathrm{g} / \mathrm{ml})$ increased phosphorylated p38 and ERK1/2 up to 1.3 and 1.5 fold compared to control (Figure 4A). Concomitantly, $10.0 \mu \mathrm{g} / \mathrm{ml}$ sesamin treatment also significantly increased phosphorylated form of p38 and ERK1/2 (1.4 and 8.8 time compare to control) (Figure 4B), while, the activation of JNK was not found. To verify that JNK was not stimulated in this treatment condition, input p-JNK loaded on the same western blot was also determined as positive 
control. Phosphorylated JNK was detected only in input lane but not in cell lysate of sesamin treatments (data are not shown).

\section{Discussion}

As mentioned concerning osteoporotic therapy, most drugs function as resorptive inhibitors. These types of drugs exhibit a negligible ability to enhance new bone synthesis.[2] Therefore, it is desirable to investigate potential anabolic agents that can correct the imbalance in the bone remodeling process. Phytochemical may be an effective addition to osteoporotic therapy. Sesamin, a major lignan component in sesame seeds, is one such promising compound, although to date there are no studies investigating the effect of sesamin on bone cell function. This report has demonstrated the efficiency of sesamin as an anabolic agent that can enhance osteoblast differentiation without effect on cell proliferation. The result showed that sesamin (at concentration $0.3-20 \mu \mathrm{g} / \mathrm{ml}$ ) did not effects osteoblast cytotoxicity or proliferation as well as ADSCs viability. After 24 treatment in hFOB1.19, sesamin potentially up-regulated genes responsible for bone formation process which are ALP, type I collagen and osteocalcin. This rapid genes induction implied that sesamin may play role since early of osteoblast differentiation process. In addition, we found that $B M P-2$ and $R u n x 2$, the well documented growth factor and transcription factor essential for osteoblast development $[6,8,9,28,29]$, were upregulated by sesamin on the hFOB1.19. This suggests that sesamin stimulate osteoblasts to be mature and function by accelerating osteoblastogenic gene expression.

The bone remodeling is well documented that mainly directed by two cell types, bone forming cells (osteoblasts) and bone removing cells (osteoclasts). Optimal functioning of these two cells is influenced by many environmental factors and signaling pathways [7,30]. We demonstrated that sesamin can activate p38 and ERK1/2 in MAPK pathway, which mediated osteoblast maturation and differentiation $[15,16]$. There is controversial evidence that MAPK signaling promotes osteoblast proliferation or differentiation [31]. Our study showed that elevation of p38 and ERK1/2 phosphorylated form is in accordance with elevated levels of gene expression essential for the mineralization process (ALP, type I collagen and $O C N$ ), which is in agreed with previous study that $\mathrm{p}-38$ plays role in phosphorylation of smad-1 and smad-5 by BMP-2 stimulation [17]. Many studies reported the role of ERK in osteogenesis by enhance ALP activity in osteoblast progenitor cells [32-34]. Interestingly, sesamin up-regulated Runx2 gene expression, in contrast to previous results reported by Xiao et al., that MAPKs can activate and phosphorylate Runx2 without affecting its expression level [35]. From our data, it may be that sesamin can stimulate osteoblast differentiation not only through p38/ERK activation but also via other signaling cascades, which should be further investigated.

ALP has been reported as a key enzyme for initiation of matrix deposition [36]. Since sesamin increased ALP activity, this may promote osteoblast differentiation. The sesamin treatment did not enhance the mineralizing effect in hFOB1.19, which might be due to a limitation on mineral deposition in this cell line. We thus performed additional experiments on ADSCs as potential sources of adult stem cells, that exhibits differentiate capacity into various of cell types [37]. Surprisingly, ADSCs can be induced by sesamin to deposit high quantity of mineralized nodules compared with control. The effect of sesamin on ADSCs implies that sesamin affected not only committed osteoblasts such hFOB, but also osteoprogenitors.

In addition to direct effects of sesamin on osteoblasts, there were indirect effects on osteoclast differentiation by up- regulating OPG expression and decreasing $R A N K L$ expression. During the bone remodeling process, there is communication among bone cells in order to modulate the homeogenesis of bone turnover [38]. The essential cross-talk, by which osteoblasts control differentiation of bone resorption cells or osteoclasts, is mediated through interaction between RANKL-expressing osteoblasts and RANK-expressing osteoclast precursors [23]. While RANKL binding leads to osteoclastogenesis activation, osteoblasts also express OPG, a decoy receptor of RANKL, leading to negatively controlled osteoclast development and further bone resorption. Treatment with sesamin at 2.5 and $5.0 \mu \mathrm{g} / \mathrm{ml}$ significantly increased the expression of $O P G$ and decreased the expression of RANKL. These results suggest that sesamin might decrease the RANKL/ OPG production ratio, resulting in indirect inhibition of osteoclastogenesis. Thus, regulation of RANKL/OPG expression may be one approach to reversing osteoporosis [2,39]. Nevertheless, sesamin $(10.0 \mu \mathrm{g} / \mathrm{ml})$ caused an elevated of RANKL gene expression. This inverse effect may be due to reciprocal regulation from its antagonist gene expression, $O P G$, to balance the expression ratio of both ligands.

Effects of sesamin on osteoblast differentiation as describe in this study is a good initiation highlight that phytochemical agent could be used as alternative therapy and prevention for bone loss disease. Since, osteoblast and osteoclast responsible for maintaining bone metabolism, thus, the effect of sesamin on osteoclast differentiation by direct and in-diract effects on osteoclast differentiation will be further investigated.

\section{Conclusions}

Whereas the anti-inflammatory, anti-allergic and neuroprotective effects of sesamin are well documented, its effect on bone cells and associated diseases are relatively 
unknown. We examined the effects of sesamin on osteoblast differentiation and mineralization. Sesamin had direct effects on osteoblasts by stimulating the expression of essential genes and key enzymes of the bone mineralization process. This stimulation might occur due to the activation of p38 and ERK1/2 MAPK signaling pathways. Besides the direct effect on osteoblasts, sesamin may indirectly control osteoclast maturation and function through regulation of the expression ratio of $R A N K L / O P G$. The effects of sesamin on in vitro bone differentiation in our study is in agreement with previous studies of Boulbaroud et al., who reported the preventive role of sesame oil in ovariectomized rats. Taken together, we concluded that sesamin is an effective candidate for bone disease therapy.

\section{Competing interest}

The authors declare that they have no competing interests

\section{Authors' contributions}

OW carried out cell cytotoxicity assay, cell proliferation assay, mineralization assay, western blotting and drafted the manuscript. KB carried out Real-time RT-PCR, ALP activity and participated in study design and data analysis. PP supervised of the study protocol, data interpretation and manuscript preparation. VR and PK supervised the study design, data interpretation and corrected the manuscript for publication. All authors read and approved the final manuscript

\section{Acknowledgements}

This research was supported by grant under the program Strategic Scholarship for Frontier Research Network for the Ph.D. Program Thai Doctoral degree, the Office of the Higher Education Commission and the Graduate School of Chiang Mai University (to OW), Center for Innovation in Chemistry (PERCH-CIC), Commission on Higher Education (to KB), and Center of Excellence Grant of Chiang Mai University (to PK).

\section{Author details}

'Thailand Excellence Center for Tissue Engineering and Stem Cells, Department of Biochemistry, Faculty of Medicine, Chiang Mai University, Chiang Mai 50200, Thailand. ${ }^{2}$ Center for Innovation in Chemistry, Department of Chemistry, Faculty of Science, Mahidol University, Bangkok, Thailand.

Received: 9 June 2011 Accepted: 30 May 2012

Published: 30 May 2012

\section{References}

1. Sambrook P, Cooper C: Osteoporosis Lancet 2006, 367(9527):2010-2018.

2. Rodan GA, Martin TJ: Therapeutic approaches to bone diseases. Science 2000, 289(5484):1508-1514.

3. Reid IR: Anti-resorptive therapies for osteoporosis. Semin Cell Dev Biol 2008, 19(5):473-478

4. Khosla S, Westendorf JJ, Oursler MJ: Building bone to reverse osteoporosis and repair fractures. $J$ Clin Invest 2008, 118(2):421-428.

5. Pittenger MF, Mackay AM, Beck SC, Jaiswal RK, Douglas R, Mosca JD, et al: Multilineage potential of adult human mesenchymal stem cells. Science 1999, 284(5411):143-147.

6. Komori T: Regulation of osteoblast differentiation by transcription factors. J Cell Biochem 2006, 99(5):1233-1239.

7. Harada S, Rodan GA: Control of osteoblast function and regulation of bone mass. Nature 2003, 423(6937):349-355

8. Yamaguchi A, Komori T, Suda T: Regulation of osteoblast differentiation mediated by bone morphogenetic proteins, hedgehogs, and Cbfa1. Endocr Rev 2000, 21(4):393-411.

9. Termaat MF, Den Boer FC, Bakker FC, Patka P, Haarman HJ: Bone morphogenetic proteins. Development and clinical efficacy in the treatmen of fractures and bone defects. J Bone Joint Surg Am 2005, 87(6):1367-1378.
10. Johnson GL, Vaillancourt RR: Sequential protein kinase reactions controlling cell growth and differentiation. Curr Opin Cell Biol 1994, 6 (2):230-238

11. Seger R, Krebs EG: The MAPK signaling cascade. FASEB J 1995, 9(9):726-735

12. Zhang W, Liu HT: MAPK signal pathways in the regulation of cell proliferation in mammalian cells. Cell Res 2002, 12(1):9-18.

13. Chang L, Karin M: Mammalian MAP kinase signalling cascades. Nature 2001, 410(6824):37-40.

14. Gallea S, Lallemand F, Atfi A, Rawadi G, Ramez V, Spinella-Jaegle S, et al: Activation of mitogen-activated protein kinase cascades is involved in regulation of bone morphogenetic protein-2-induced osteoblast differentiation in pluripotent C2C12 cells. Bone 2001, 28(5):491-498.

15. Ge C, Xiao G, Jiang D, Franceschi RT: Critical role of the extracellular signal-regulated kinase-MAPK pathway in osteoblast differentiation and skeletal development. J Cell Biol 2007, 176(5):709-718.

16. Lai CF, Chaudhary L, Fausto A, Halstead LR, Ory DS, Avioli LV, et al: Erk is essential for growth, differentiation, integrin expression, and cell function in human osteoblastic cells. J Biol Chem 2001, 276(17):14443-14450.

17. Noth U, Tuli R, Seghatoleslami R, Howard M, Shah A, Hall DJ, et al: Activation of p38 and Smads mediates BMP-2 effects on human trabecular bone-derived osteoblasts. Exp Cell Res 2003, 291(1):201-211.

18. Jeng KCG, Hou RCW: Sesamin and Sesamolin: Natures Therapeutic Lignans. Curr Enzym Inhib 2005, 1:11-20.

19. Boulbaroud S, Mesfioui A, Arfaoui A, Ouichou A, El-Hessni A: Preventive effects of flaxseed and sesame oil on bone loss in ovariectomized rats. Pak J Biol Sci 2008, 11(13):1696-1701.

20. Livak KJ, Schmittgen TD: Analysis of relative gene expression data using real-time quantitative PCR and the 2(-Delta Delta $C(T)$ ) Method. Methods 2001, 25(4):402-408.

21. Gregory CA, Gunn WG, Peister A, Prockop DJ: An Alizarin red-based assay of mineralization by adherent cells in culture: comparison with cetylpyridinium chloride extraction. Anal Biochem 2004, 329(1):77-84.

22. Mosmann T: Rapid colorimetric assay for cellular growth and survival: application to proliferation and cytotoxicity assays. $J$ Immunol Methods 1983, 65(1-2):55-63.

23. Boyle WJ, Simonet WS, Lacey DL: Osteoclast differentiation and activation. Nature 2003, 423(6937):337-342.

24. Reinholz GG, Getz B, Pederson L, Sanders ES, Subramaniam M, Ingle JN, et al: Bisphosphonates directly regulate cell proliferation, differentiation, and gene expression in human osteoblasts. Cancer Res 2000, 60(21):6001-6007.

25. Setzer B, Bachle M, Metzger MC, Kohal RJ: The gene-expression and phenotypic response of hFOB 1.19 osteoblasts to surface-modified titanium and zirconia. Biomaterials 2009, 30(6):979-990

26. Lecoeur L, Ouhayoun JP: In vitro induction of osteogenic differentiation from non-osteogenic mesenchymal cells. Biomaterials 1997, 18(14):989-993.

27. Strem BM, Hicok KC, Zhu M, Wulur I, Alfonso Z, Schreiber RE, et al: Multipotential differentiation of adipose tissue-derived stem cells. Keio $J$ Med 2005, 54(3):132-141.

28. Singhatanadgit W, Salih V, Olsen I: RNA interference of the BMPR-IB gene blocks BMP-2-induced osteogenic gene expression in human bone cells. Cell Biol Int 2008, 32(11):1362-1370.

29. Nakashima K, de Crombrugghe B: Transcriptional mechanisms in osteoblast differentiation and bone formation. Trends Genet 2003, 19 (8):458-466.

30. Sims NA, Gooi JH: Bone remodeling: Multiple cellular interactions required for coupling of bone formation and resorption. Semin Cell Dev Biol 2008, 19(5):444-451.

31. Schindeler A, Little DG: Ras-MAPK signaling in osteogenic differentiation: friend or foe? J Bone Miner Res 2006, 21(9):1331-1338.

32. Lou J, TU Y, Li S, Manske PR: Involvement of ERK in BMP-2 induced osteoblastic differentiation of mesenchymal progenitor cell line C3H10T1/2. Biochem Biophys Res Commun 2000, 268(3):757-762.

33. Celil AB, Campbell PG: BMP-2 and insulin-like growth factor-I mediate Osterix (Osx) expression in human mesenchymal stem cells via the MAPK and protein kinase D signaling pathways. J Biol Chem 2005, 280 (36):31353-31359.

34. Jaiswal RK, Jaiswal N, Bruder SP, Mbalaviele G, Marshak DR, Pittenger MF: Adult human mesenchymal stem cell differentiation to the osteogenic or adipogenic lineage is regulated by mitogen-activated protein kinase. J Biol Chem 2000, 275(13):9645-9652. 
35. Xiao G, Jiang D, Thomas P, Benson MD, Guan K, Karsenty G, et al: MAPK pathways activate and phosphorylate the osteoblast-specific transcription factor, Cbfa1. J Biol Chem 2000, 275(6):4453-4459.

36. Balcerzak M, Hamade E, Zhang L, Pikula S, Azzar G, Radisson J, et al: The roles of annexins and alkaline phosphatase in mineralization process. Acta Biochim Pol 2003, 50(4):1019-1038.

37. Gimble JM, Katz AJ, Bunnell BA: Adipose-derived stem cells for regenerative medicine. Circ Res 2007,100(9):1249-1260.

38. Matsuo K, Irie N: Osteoclast-osteoblast communication. Arch Biochem Biophys 2008, 473(2):201-209.

39. Bekker PJ, Holloway D, Nakanishi A, Arrighi M, Leese PT, Dunstan CR: The effect of a single dose of osteoprotegerin in postmenopausal women. J Bone Miner Res 2001, 16(2):348-360.

doi:10.1186/1472-6882-12-71

Cite this article as: Wanachewin et al: Sesamin stimulates osteoblast differentiation through p38 and ERK1/2 MAPK signaling pathways. BMC Complementary and Alternative Medicine 2012 12:71.

\section{Submit your next manuscript to BioMed Central and take full advantage of:}

- Convenient online submission

- Thorough peer review

- No space constraints or color figure charges

- Immediate publication on acceptance

- Inclusion in PubMed, CAS, Scopus and Google Scholar

- Research which is freely available for redistribution 